\title{
A LENDA DA ESPADA DE DAMASCO - HISTÓRIA E TECNOLOGIA
}

Christian Slaughter'

Hélio Goldenstein ${ }^{2}$

\section{Resumo}

A Espada de Damasco é um sabre que equipou os exércitos muçulmanos medievais. Esta arma está intimamente associada à civilização islâmica. As excelentes propriedades mecânicas, seu significado simbólico, a arte e habilidade envolvida em sua produção, assim como os belos desenhos ondulados visíveis em sua lâmina elevaram esta arma à condição de lenda. Sua principal matéria prima era o aço de cadinho de alto teor de carbono. Evidências revelam que não havia uma única forma de se produzir este aço. O presente artigo se propõe a discutir seus prováveis processos de produção assim como o mecanismo de formação do padrão de Damasco.

Palavras-chave: Espada de Damasco; Aço de damasco; Wootz; Aço de cadinho.

\section{THE LEGEND OF THE DAMASCUS SWORD - HISTORY AND TECHNOLOGY}

\begin{abstract}
The Damascus sword is a saber that was the weapon of choice of the Muslim medieval armies. This weapon is closely related to Islamic civilization. Its great mechanical properties, simbolic value, the art and technical skill necessary to its production, as much as its pleasant wavy pattern turned it a legend. Its main raw material was high carbon crucible steels. This paper debates the probable production processes and the mechanism by which Damascus pattern are formed. Keywords: Damascus sword; Damascus steel; Wootz steel; Crucible steel.
\end{abstract}

\section{INTRODUÇÃO}

O rei Ricardo empunhava uma "broadsword", espada manejada a duas mãos, grande e pesada. Saladino, por outro lado, utilizava um sabre fino e leve, cuja lâmina parecia ter "dez milhões de linhas" e uma cor azulada opaca. Era a espada de Damasco. Com a intenção de mostrar a superioridade da espada europeia, o rei Ricardo, vendo uma maça de aço. golpeia-a com a espada quebrando-a. Saladino, por sua vez, coloca um leve lenço dobrado ao meio sobre o fio de seu sabre e após alguns instantes puxa-o rapidamente cortando o lenço em dois em pleno ar [I].

Extraída da obra de Walter Scott [I], O Talismã, de 1825, esta passagem descreve 0 encontro do rei Ricardo Coração de Leão com o sultão Saladino durante as cruzadas. Embora se trate de uma ficção, a narrativa explora bem a reputação da lendária Espada de Damasco.

A Espada de Damasco (Figura I) era um sabre que equipou os exércitos muçulmanos medievais. Está de tal forma associada à civilização islâmica que se tornou um símbolo desta cultura. Esta espada se caracterizava pelas ótimas propriedades mecânicas [2] e pelos belos desenhos ondulados (Figura 2), formados por regiões da lâmina de tons claros e escuros alternados, visíveis a olho nu, efeito este produzido após polimento e, às vezes, ataque químico apropriado. Estes atributos, somados à sua mística e arte, alçaram esta arma à condição de lenda, cuja fama era tal, que os desenhos ondulados visíveis [3] - correspondentes ao que se denomina hoje de macrografia do aço - acabaram se tornando uma garantia da qualidade da espada. Inúmeras tentativas de reproduzi-la e imitá-la ocorreram tanto no Oriente como na Europa desde - período Medieval [4] destas tentativas surgiram outros produtos siderúrgicos obtidos por caldeamento, denominados "falsos damascos", inclusive o Nihon-to, o aço das espadas japonesas. Modernamente seu estudo esteve na origem da própria Metalografia [5] e impulsionou o desenvolvimento de novos aços (tais como os aços-ferramenta hipereutetóides, os aços para rolamento e os "pin point carbide steel" (DIN I20 Cr2).

O nome Espada de Damasco parece ter se originado do fato dos guerreiros cruzados europeus terem entrado em contato com a espada pela primeira vez nos mercados da cidade medieval de Damasco [6], o que

'Engenheiro Metalurgista, Departamento de Engenharia Metalúrgica e Materiais, Escola Politécnica, Universidade de São Paulo - USP, São Paulo, SP, Brasil.E-mail: christianslaughter20I2@hotmail.com

${ }^{2}$ Engenheiro Metalurgista, Doutor, Professor Titular, Departamento de Engenharia Metalúrgica e de Materiais, Universidade de São Paulo - USP, São Paulo, SP, Brasil.E-mail: hgoldens@usp.br 
não implica que fossem produzidas em tal cidade, como afirmam alguns autores [4]. Damasco era apenas um dos vários centros de comércio, onde caravanas vindas tanto do Ocidente como do Oriente se encontravam e negociavam tais artigos [7]. Feuerbach [8] sugere que 0 nome poderia ter vindo do termo "damas", que em árabe significa água [8], imagem frequentemente utilizada para descrever o padrão visual da lâmina.

Entre os séc. VIII e XIII d.C. ○ mundo muçulmano viveu seu apogeu como civilização. $O$ alto grau de desenvolvimento alcançado por esta sociedade deveu-se, em grande medida, à sua capacidade de assimilar características dos diversos povos com os quais conviveu. $O$ aço de cadinho, matéria prima da espada de Damasco, era proveniente da Índia e da Ásia Central. As invasões dos povos nômades da Ásia Central trouxeram inovações, sendo claramente responsáveis pela introdução de diversas inovações no campo militar, como o sabre $[9,10]$. $O$ artigo discutirá a origem e processo de sua matéria prima, o aço de cadinho, assim como suas possíveis rotas de fabricação. As modernas hipóteses da formação do padrão damasceno propostas por Sherby e Wadsworth [II] e Verhoeven et al. [12] serão debatidas e a recente descoberta de que este material apresenta propriedades superplásticas [13] em uma ampla faixa de temperaturas, o que explica a viabilidade de seu forjamento, apesar do elevado teor de carbono.

Embora fosse instrumento de violência, a espada de Damasco também possuía significado simbólico, sua manufatura requeria controle e perícia e seus suaves

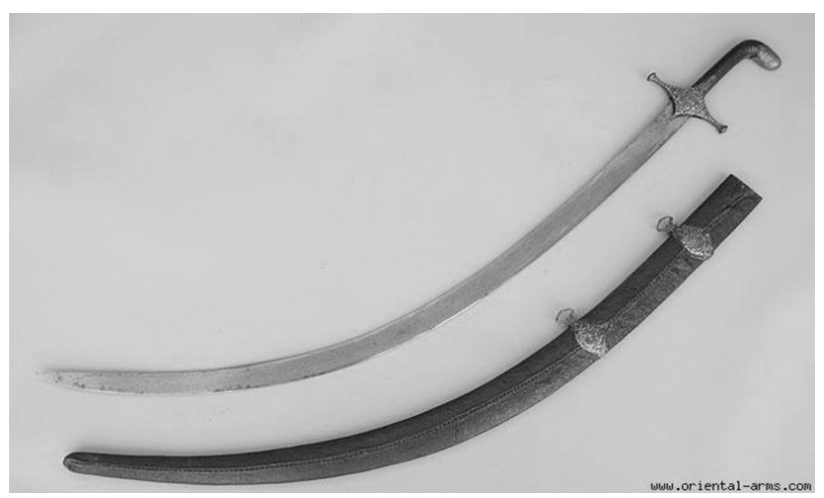

Figura I. Espada de Damasco persa.

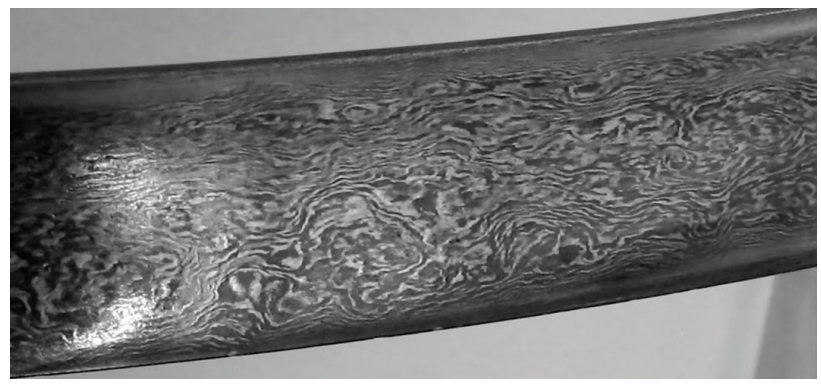

Figura 2. "Águas" do padrão damasceno da lâmina em detalhe [14]. desenhos remetem a uma arte delicada. $\mathrm{O}$ aço da lâmina testemunha o domínio de um complexo processo de produção, indicando o estágio tecnológico em que se encontrava a civilização islâmica medieval. As lendas a ela associadas, sua forma, decoração e inscrições contam com detalhes o contexto histórico, social e cultural no qual foi concebida.

As diferentes rotas de produção do aço de cadinho revelam que havia mais de uma maneira de produzi-lo. $\mathrm{Na}$ realidade, havia muitas rotas, assim como muitas eram suas regiões de origem. Diferente do que se acreditava, o wootz indiano não era a única matéria prima, estudos recentes mostram que aço de cadinho de alto teor de carbono também foi produzido na Ásia Central, ao longo da Rota da Seda.

A compreensão da estrutura do aço de Damasco possui sua própria história. Muito esforço foi consagrado por cientistas durante mais de um século até que se compreendesse a natureza deste aço. Duas explicações sobre o surgimento do padrão de Damasco se destacam atualmente. Para J. Verhoeven et al. [15] as partículas de cementita alinhadas que produzem o padrão visual, são formadas em regiões interdendríticas como consequência da segregação de impurezas durante a solidificação. Neste método, a cementita que produz o padrão se forma durante os ciclos térmicos do forjamento. Por outro lado, para Sherby e Wadsworth [I I], as partículas de carboneto alinhadas correspondem à rede de cementita no contorno de grão, formada durante $\circ$ resfriamento após a transposição da linha $A_{c m}$. Esta rede é fragmentada e alinhada durante o forjamento em faixa específica de temperatura.

\section{A MATÉRIA-PRIMA}

A espada de Damasco podia ser produzida através de diferentes processos ou rotas $[16,17]$. $O$ processo pode ser dividido em duas grandes etapas. A primeira consistia na produção do lingote de alto teor de carbono (aço UHC - Ultra High Carbon - são ligas ferro-carbono de teor de carbono entre I,0\% e 2, I\%.). A segunda etapa era o forjamento do lingote em lâmina.

\section{I Rota A}

Uma das formas utilizadas para produzir o aço de cadinho consistia em selecionar o minério, moê-lo e lavá-lo. Em seguida, o minério era secado e carregado junto com carvão vegetal ou madeira e folhas de plantas consideradas sagradas. Uma vez fechados com argila eram levados ao forno. O conjunto de cadinhos era aquecido por cerca de 50 horas e, então, deixado a resfriar lentamente. Durante o aquecimento, primeiramente se forma o ferro esponja, produto da redução. O carbono proveniente do carvão passa, então, a difundir pela superfície da massa de ferro recém reduzida. $O$ carbono continua, 
assim, migrando para o interior do material formando um gradiente de concentração. As regiões mais externas, ricas em carbono, começam a fundir até que todo o material se torne líquido, caso a temperatura fosse alta o suficiente.

Imaginemos uma liga com I,8\%C seja mantida a $1.400^{\circ} \mathrm{C}$ (Figura 3), estando, portanto no estado líquido. Se reduzirmos lentamente a temperatura do sistema, ao chegarmos a $1.380^{\circ} \mathrm{C}$ começará a solidificação. Austenita começará a formar-se durante o resfriamento até $1.190^{\circ} \mathrm{C}$, quando todo o líquido tenha se transformado em sólido. Seguindo o resfriamento, alcançamos a temperatura de $1.065^{\circ} \mathrm{C}$. Neste momento cementita pró-eutetóide começa a precipitar nos contornos de grão até atingirmos $727^{\circ} \mathrm{C}$, momento em que toda a austenita remanescente se transforma em perlita. Assim, o produto obtido será um lingote de grandes grãos com estrutura perlítica dentro de uma rede contínua de cementita pró-eutetóide [17].

\subsection{Rota B}

Este método, que chamaremos de cofusão, termo cunhado por Needham [19], consiste em misturar ferro fundido e ferro esponja para se obter aço com um teor de carbono intermediário entre os dois. Depois de carregado com as proporções corretas de ferro esponja e de ferro fundido, o cadinho era tipicamente colocado no forno a temperaturas entre $1.200^{\circ} \mathrm{C}$ e $1.400^{\circ} \mathrm{C}$. Este processo era conhecido na China [19] e também na região de Hyderabad, Índia [20].

Imaginemos um cadinho com $70 \%$ de ferro esponja, cujo teor de carbono é praticamente zero, e $30 \%$ de ferro fundido com $4 \% \mathrm{C}$. Coloca-se então o cadinho em um forno a $1.250^{\circ} \mathrm{C}$. A esta temperatura, todo o ferro fundido torna-se líquido, enquanto o ferro esponja, devido a seu maior ponto de fusão, permanece sólido. Entretanto, conforme o tempo passa, carbono do banho difunde para a superfície do sólido, enriquecendo-a até que esta atinja I,5\%C. Ao exceder tal teor, o sólido funde e se incorpora ao líquido preexistente. Este processo continua até que o líquido tenha seu teor de carbono reduzido a 3,5\%. O carbono da superfície difunde para o interior do sólido, permitindo que o líquido, ao fornecer carbono para a massa sólida, passe a solidificar com I,5\% Cem sua superfície, até que todo ele seja exaurido. $O$ resultado final será uma massa sólida heterogênea cuja composição variará entre $0 \%$ e $1,5 \%$, podendo ser homogeneizado posteriormente $[16,19]$.

É interessante notar que, modernamente, pesquisadores como Goldenstein et al. [2I] e Langford e Cunningham [22] desenvolveram processos denominados "solidificação difusional", cujos princípios são similares ao processo milenar de cofusão.

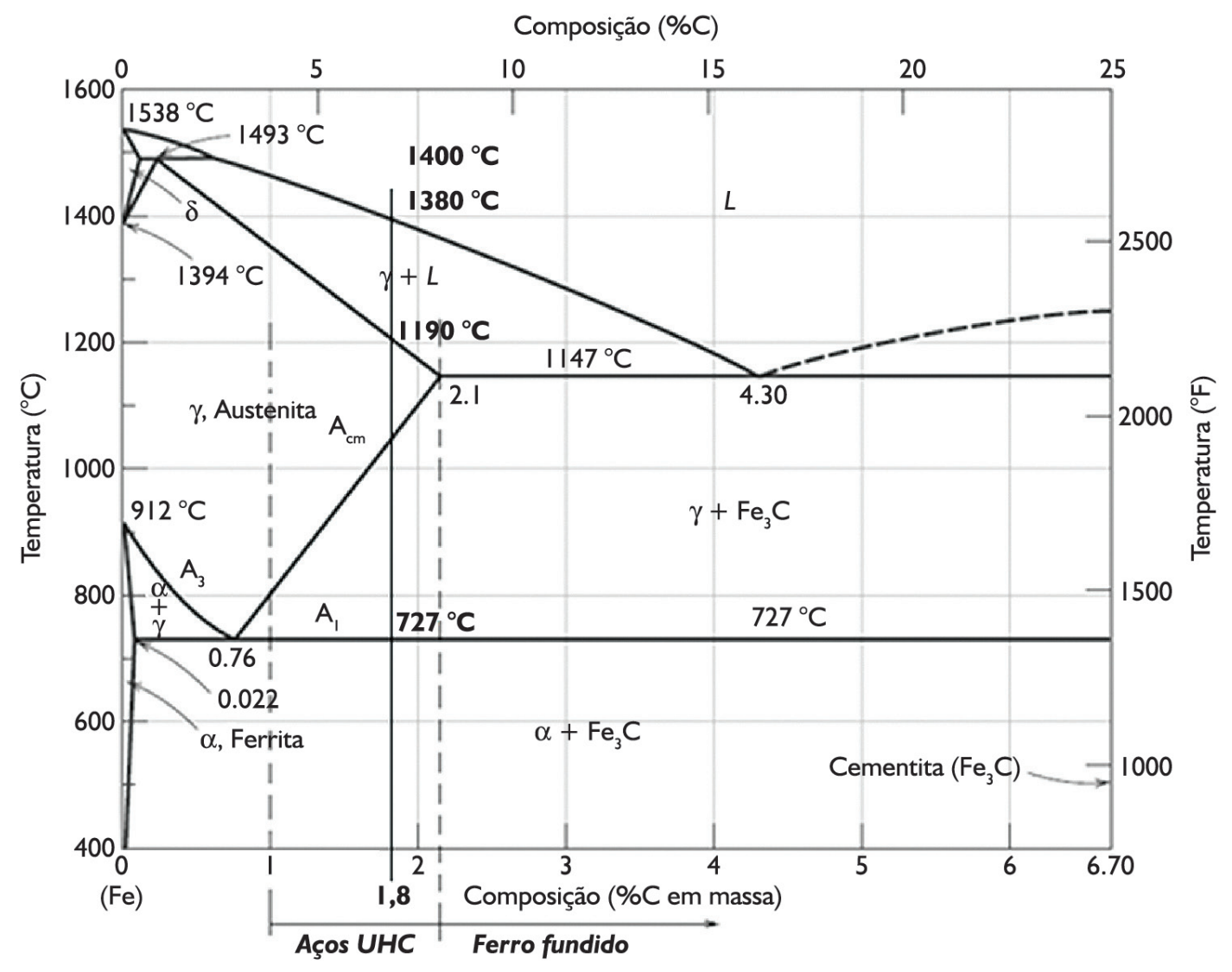

Figura 3. Diagrama Fe-C. Classificação em função da faixa de teor de carbono [18]. 


\subsection{Rota C}

Este método é o oposto do primeiro. Aqui, ferro fundido com alto teor de carbono era colocado no forno. Dependendo de sua composição, esta podia fundir tão logo quanto a temperatura excedesse $1.200^{\circ} \mathrm{C}$. A esta temperatura, a oxidação na superfície do banho ocorre rapidamente, promovendo a descarbonetação da liga. A casca de óxido formada na superfície durante a oxidação era retirada regularmente com o intuito de não bloquear o acesso do oxigênio ao metal líquido. $O$ carbono dissolvido reage com o oxigênio sendo extraído na forma de $\mathrm{CO}_{2}$. Conforme o teor de carbono no metal diminui, seu ponto de fusão aumenta, promovendo sua solidificação gradual. O processo termina com a liga já no estado sólido. $O$ produto final resfriava então lentamente para permitir sua homogeneização.

Uma variação deste método era realizar um procedimento similar, entretanto, todo no estado sólido. Nesse caso, as temperaturas necessárias eram da ordem de $1.000^{\circ} \mathrm{C}$ e tempo necessário, consideravelmente maior $[16,19]$.

\section{ESTUDOS MODERNOS SOBRE O AÇO DE DAMASCO}

Os primeiros textos citando o aço de Damasco aparecem ainda no séc. IX com al Kindi apud Khorasani [6], um dos maiores filósofos/cientistas islâmicos medievais $[6,16]$. Os primeiros estudos científicos do aço de Damasco começaram com Pearson, na Inglaterra em 1795, que em seu trabalho sobre o aço indiano "wootz" concluiu que este se tratava mais de um aço do que de ferro. Em I804 Mushet apud Sherby e Wadsworth [17] concluiu que o wootz continha alto teor de carbono e que isso podia ter relação com a formação do padrão de damasco das espadas. Em I820, instigado pelos trabalhos de Mushet apud Sherby e Wadsworth [17], o cientista britânico Michael Faraday apud Sherby e Wadsworth [17], que era filho de ferreiro e que ficaria mais conhecido por seus trabalhos em eletromagnetismo, também consagrou esforços para entender o wootz [4, 17]. Na França, liderando um grupo de cientistas, Breant chegou a conclusão semelhante à de Mushet. Breant apud Sherby e Wadsworth [17], em 1823, concluiu que a estrutura damascena era formada de regiões com aço de composição aproximadamente eutetóide e outras de aço com alto teor de carbono [17].

Na Rússia, dando sequencia aos estudos de Anossoff apud Sherby e Wadsworth [17] e D. K. Tchernoff apud Sherby e Wadsworth [17], Belaiew apud Sherby e Wadsworth [17], em 1906, reconheceu que o padrão tratava-se de carboneto pro-eutetóide em uma matriz de composição eutética. Além disso, atribuiu, corretamente, a maleabilidade deste aço à morfologia esferoidizada da cementita.
Ainda no séc. $X X$, por meio da microscopia óptica, associou-se o padrão de Damasco à presença alternada e alinhada de cementita fragmentada (Figura 4) [17].

$\mathrm{Na}$ década de 1960, a publicação de artigos de C. $S$. Smith [5] sobre o tema alimentou uma nova onda de interesse sobre $o$ assunto. Atualmente pode-se encontrar vasta literatura sobre o aço de Damasco [23].

Hipóteses consistentes sobre os mecanismos do surgimento das faixas de partículas de cementita, que caracterizam o aço de Damasco, só foram desenvolvidas no final do séc. $X X$ [4], principalmente por Sherby [24] e J. Verhoeven et al. [15].

\section{I O. D. Sherby [II]}

Embora o wootz já fosse conhecido na Ásia há dois milênios, o estudo sistemático dos aços UHC começou apenas na década de 1970, nos EUA, durante pesquisas sobre superplasticidade de aços com alto teor de carbono conduzidos por Oleg Sherby e Jeffrey Wadsworth [13]. A superplasticidade se caracteriza pela manifestação de grande dutilidade (numa certa faixa temperaturas) em aços que, devido ao seu alto teor de carbono, são normalmente associados à fragilidade. Durante estas pesquisas sobre comportamento superplástico de aços UHC, verificou-se que estes apresentavam composição semelhante às das renomadas espadas de Damasco medievais [13]. Assim, esta propriedade foi, provavelmente, um fator importante para $\circ$ forjamento destas armas.

Sherby e Wadsworth [13], voltando seu interesse para $\circ$ aço de Damasco, concluiu que as partículas de carboneto de ferro grosseiras alinhadas se originam da cementita pro-eutetóide formada nos contornos de grão durante o resfriamento $[4,17,24]$, tal como descrito previamente pela Rota $A$.

A cementita que se forma nos contornos durante o resfriamento produz uma rede contínua que encerra os grãos austeníticos. Sendo extremamente dura, é responsável pela fragilidade do material, uma vez que permite que

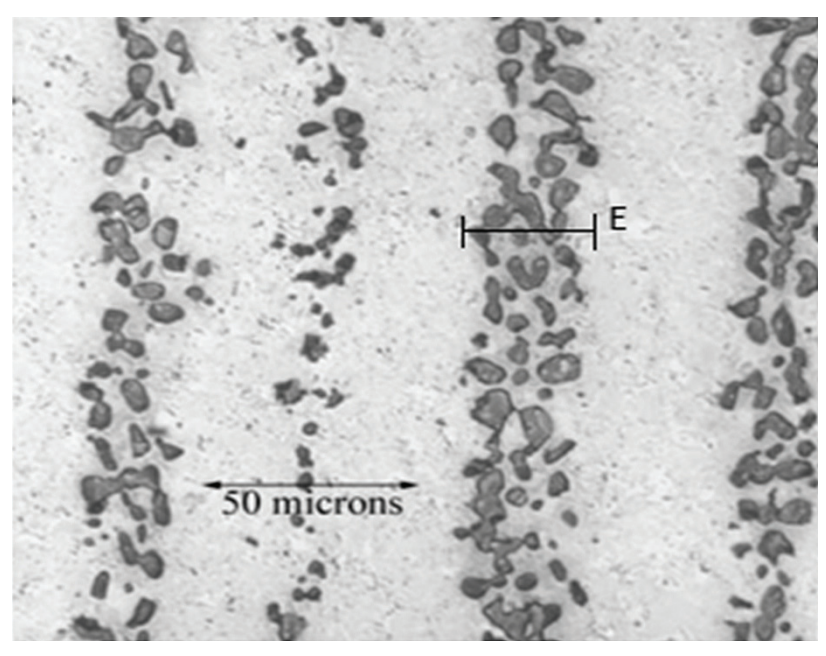

Figuras 4. Bandas de partículas de cementita (região escura) dentro de uma matriz ferrítica (região clara da figura). 
trincas produzidas nesta fase frágil se propaguem ao longo da rede $[\mathrm{II}]$. Este problema, entretanto, podia ser superado por um cuidadoso forjamento inicial que fragmenta e esferoidiza os filmes de cementita de contornos de grão, além de um tratamento prévio de descarbonetação superficial que tinha como propósito produzir um fino envelope dútil de ferro baixo carbono no lingote a ser forjado. A forja subsequente é realizada em ciclos à temperaturas abaixo da linha $A_{c m}$, isto rompe e fragmenta a cementita pro-eutetóide ao mesmo tempo em que impede que volte a se dissolver na austenita, permitindo, por outro lado, que as partículas geradas permaneçam próximas formando camadas dentro de uma matriz ferrítica. Assim, as partículas de cementita alinhadas que caracterizam o padrão de Damasco se originam da cementita pro-eutetóide dos contornos de grão que só são fragmentadas em função da ação mecânica do forjamento. Uma informação adicional é que a forja, nessa faixa de temperaturas, é favorecida pelo fenômeno da superplasticidade, manifestado por aços com tal teor de carbono.

\subsection{John D. Verhoeven [12]}

John D. Verhoeven [15], da Universidade de lowa, realizou uma série de experimentos em parceria com o ferreiro Pendray e também apresentou uma explicação do mecanismo de formação do padrão de damasco. De acordo com Verhoeven et al. [15], as faixas de partículas de cementita são produzidas em regiões interdendríticas [4]. Estas regiões, por apresentarem maior concentração de elementos tais como Vanádio, devido à segregação ocorrida durante a solidificação, seriam os locais preferenciais de nucleação das partículas de carboneto que constituem as faixas (Figura 5) [15]. A nucleação e crescimento de tais partículas ocorreriam devido aos ciclos térmicos empregados durante o forjamento [12,25].

Verhoeven [2] observou um paralelo entre o padrão damasceno das espadas e um fenômeno comum também em aços hipoeutetóides, conhecido como bandeamento.

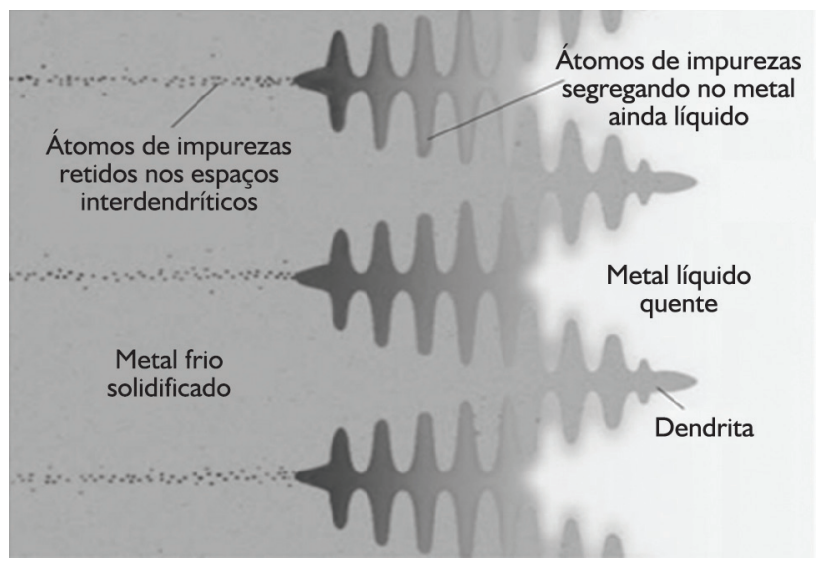

Figura 5. Segregação. Soluto (impurezas) fica retido entre dendritas durante a solidificação [26].
O bandeamento é a formação alternada de regiões ferríticas e perlíticas que pode surgir em decorrência da microssegregação de certos elementos de liga nos espaços interdendríticos [27] destes aços. Durante o processo de solidificação do aço, a interface sólido/líquido avança no sentido do último. Elementos de liga presentes tendem a ser rejeitados para a porção líquida remanescente, devido à maior solubilidade destes elementos no líquido do que no sólido. Assim, a proporção de líquido vai diminuindo durante a solidificação, enquanto sua concentração em tais elementos aumenta, concentrando-se, nas últimas regiões a solidificar, os espaços interdendríticos. Consideremos um caso típico de um aço com cerca de $1 \% \mathrm{Mn}$ e baixo S. O Mn tem efeito estabilizador para a austenita, abaixando a posição da linha $\mathrm{A}_{3}$ do diagrama de fases $\mathrm{Fe}-\mathrm{C}$ (Figura 3). Durante o resfriamento, ao se transpor a linha $A_{3}$, as regióes centrais das dendritas, com menor teor de Mn serão as primeiras a sofrer transformação, produzindo ferrita, expulsando carbono para as regiões interdendríticas que, por sua vez, formarão perlita em um momento posterior. Assim, o material apresentaria faixas perlíticas e ferríticas alternadas [2,27].

Em um primeiro momento, Verhoeven [2] acreditou ser $\mathrm{P}$ ○ principal responsável pelo surgimento de cementita interdendrítica. Esta poderia formar-se durante a solidificação, mesmo com teores de carbono abaixo da solubilidade máxima deste na austenita à temperatura eutética, como sugeriu Smith [28]. Isso poderia ocorrer devido à ação do $P$, que acima de certos teores pode promover condições de não-equilíbrio durante o resfriamento.

Posteriormente, novos experimentos revelaram que o padrão também podia surgir a partir de lingotes com baixíssimos níveis de $P$, excluindo este elemento como o principal responsável pela produção das águas. Observou-se que, austenitizando amostras que já apresentavam o padrão, eliminava-se totalmente as ondulações visíveis. Entretanto, uma subsequente aplicação de ciclos térmicos de aquecimento entre $500^{\circ} \mathrm{C}$ e cerca de $80^{\circ} \mathrm{C}$ abaixo da linha $A_{c m}$, o padrão damasceno retornava gradualmente, na medida em que os ciclos se repetiam. Estes experimentos foram cruciais para estabelecer que as partículas de cementita podiam ser formadas mesmo sem deformação mecânica, diferente da hipótese de Sherby e Wadsworth [II].

Um novo panorama surgiu quando o pesquisador passou a utilizar ferro Sorel como parte da carga. Esta matéria prima contém impurezas, tais como $\mathrm{V}$ e $\mathrm{Cr}$. As experiências distinguiram claramente que as lâminas que acabaram exibindo o padrão após o processo termomecânico haviam sido aquelas produzidas com ferro Sorel. Embora em quantidades extremamente pequenas, esses elementos formadores de carboneto pareciam ser responsáveis pela formação das bandas. 
Verhoeven et al. [25] propõe que a formação das faixas ocorre durante e, devido, aos ciclos térmicos. A cada ciclo, as partículas de cementita, nucleadas nas regiões interdendríticas, engrossam à custa das menores pelo mecanismo de Ostwald ripening. Além disso, devido à segregação de certos elementos nas regiões interdendríticas, o crescimento e a diminuição das partículas de carboneto nestas regiões são retardados devido à diminuição da mobilidade da interface austenita/cementita [15]. Assim, durante os ciclos, o aumento da temperatura promove a dissolução das pequenas partículas de cementita, principalmente nas regiões dendríticas, pobres em elementos segregados, enquanto nas regiões interdendríticas, maior proporção de partículas sobreviverá. 0 resfriamento subsequente permitirá 0 crescimento das partículas que não foram dissolvidas nas regiões segregadas, mas não a reconstituição das partículas que foram totalmente dissolvidas nas regióes dendríticas, uma vez que isso exigiria nova nucleação, o que é energeticamente desfavorável. $O$ resultado será uma série de partículas de cementita em faixas, cuja distância corresponde ao espaçamento esperado entre as dendritas após a deformação imposta pelo forjamento. A proposta de Verhoeven [29] sobre a origem das faixas de partículas de cementita o fez formular uma hipótese que explicasse $o$ aparente fim da produção da espada de Damasco, ainda em meados do século XIX. Segundo ele, a produção das lâminas pode ter cessado como consequência do esgotamento das jazidas de minério que continham as impurezas relacionadas à formação do padrão [29].

\section{EXPERIMENTO DE REPRODUÇÃO DO AÇO DE DAMASCO}

\section{I Materiais e Métodos}

Carregou-se um cadinho de alumina de pequenas dimensões com $350 \mathrm{~g}$ de $\mathrm{Fe}$ de alta pureza, 7,35 g e carbono grafite de $99 \%$ de pureza. O conjunto foi colocado em um forno de indução com atmosfera inerte. $O$ aquecimento foi lento, atingindo $1.400^{\circ} \mathrm{C}$. Uma vez que o metal fundiu, o forno foi desligado e o lingote foi deixado em seu interior para solidificar e resfriar.

Uma vez obtido o aço UHC, procedeu-se da seguinte forma; Primeiro, o material foi austenitizado a I. $150^{\circ} \mathrm{C}$. Este tratamento tem por objetivo dissolver totalmente a cementita na austenita, para, em seguida, durante lento resfriamento, permitir que 0 carboneto precipite exclusivamente nos contornos de grão.

Por último, o material é aquecido novamente e mantido durante 3 horas a $800^{\circ} \mathrm{C}$. Este procedimento visa produzir uma descarbonetação superficial (Figura 6) no lingote, que age como um envelope dútil que impede que as trincas produzidas na cementita durante o forjamento se propaguem até a superfície, provocando o indesejado rompimento do material [30].
Finalmente $\circ$ lingote foi forjado pelo experiente ferreiro Remo Nogueira. Realizada entre $650^{\circ} \mathrm{C}$ e $750^{\circ} \mathrm{C}$, a forja rompe, fragmenta e alinha a cementita, formando faixas de partículas grosseiras de carboneto dentro de uma matriz ferrítica com carbonetos finos e esferoidizados. São as faixas formadas por estas partículas que produzem os desenhos de damasco. $O$ processo todo termina quando os desenhos (Figuras 7 e 8 ) são revelados após cuidadoso polimento e ataque químico específico.

\subsection{Resultados e Discussão}

Uma bem sucedida tentativa de reprodução do aço de Damasco foi realizada nos laboratórios do Departamento de Engenharia Metalúrgica da Universidade de São Paulo.

A fusão da carga no forno de indução produziu um lingote UHC com I,6\%C com a microestrutura desejada (Figura 9). Realizou-se o tratamento de austenitização a I. $150^{\circ} \mathrm{C}$ seguida de recozimento a $800^{\circ} \mathrm{C}$, o que produziu

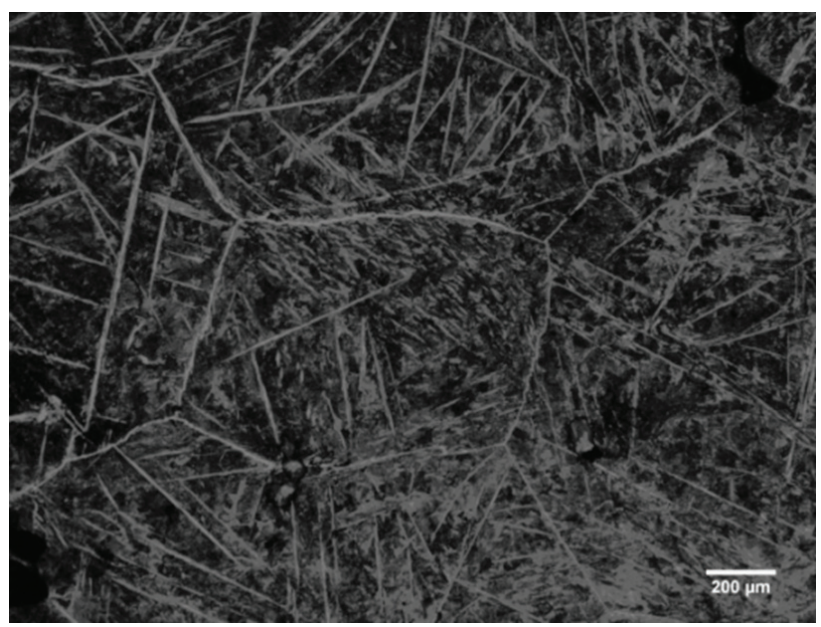

Figura 6. Camada descarbonetada após recozimento de 3 horas a $800^{\circ} \mathrm{C}$.

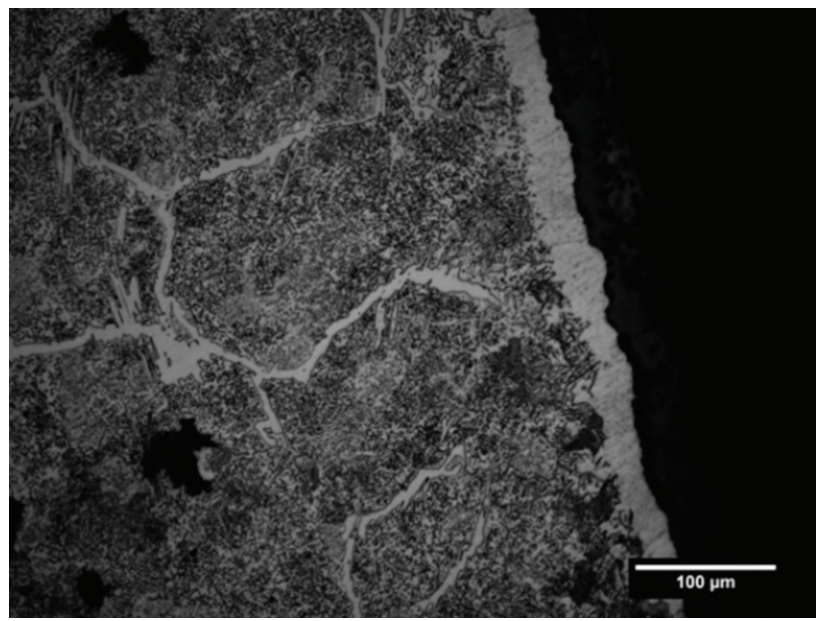

Figuras 7. Padrão damasceno revelado após polimento e ataque. Macrografia da amostra após ataque com nital $2 \%$. 


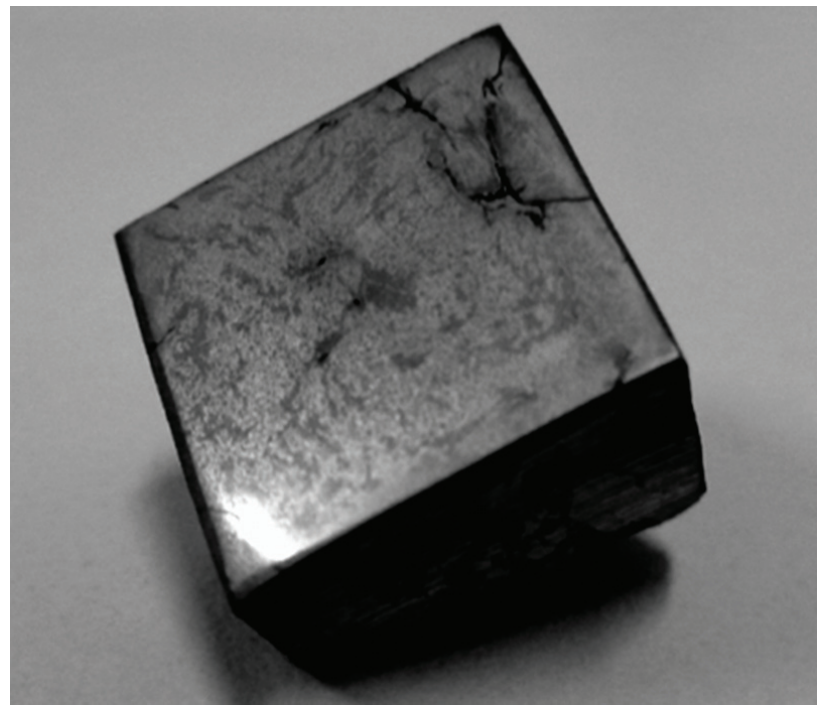

Figura 8. Macrografia obtida com lupa. Ataque com nital 2\%. É possível observar que alguns poros não caldearam totalmente durante o forjamento.

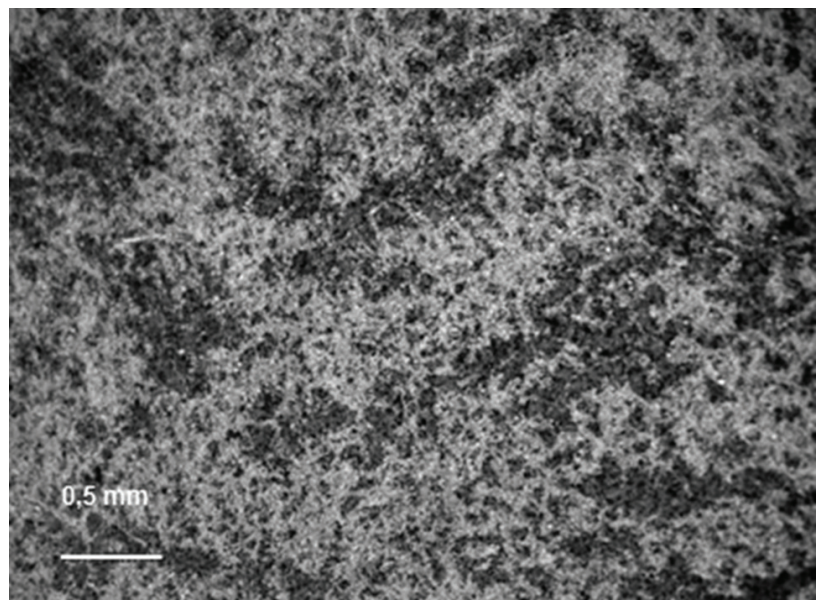

Figura 9. Aço UHC no estado bruto de fusão. Pode-se notar a rede contínua de carboneto delimitando os contornos de grão, assim como a presença massiva de cementita de Widmanstatten.

uma fina camada superficial descarbonetada, tal como previsto (Figura 6). Esta camada permitiu a execução da próxima etapa, o forjamento. Este forjamento, realizado de forma controlada em faixa estreita de temperatura, rompe e alinha a cementita que havia precipitado nos contornos de grão. Este alinhamento regular das partículas grosseiras de carboneto produziu o padrão de damasco final (Figuras 6 a 8).

\section{CONCLUSÃO}

A literatura descreve uma série de maneiras diferentes de se reproduzir tal aço $[16,30]$. A produção da matéria prima do aço de Damasco, por si só, representou um grande desafio para este estudo, só superado após uma serie de tentativas.

Seguindo um roteiro inspirado na rota $A$ descrita acima, partindo de ferro extra doce e carbono pulverizado, produziu-se um lingote UHC. Em seguida procedeu-se aos tratamentos de austenitização e recozimento, para que a cementita precipitasse nos contornos de grão e para produzir a camada descarbonetada, respectivamente. Finalmente, $\circ$ forjamento cuidadoso à temperatura controlada fragmentou e alinhou a cementita produzindo o padrão damasceno desejado. Assim, foi possível reproduzir o padrão por meio da rota $A$.

\section{I Considerações Finais}

As duas explicações para o surgimento das "águas" (hipóteses de Verhoeven e Sherby) atribuem sua formação a mecanismos diferentes. Entretanto, não parece improvável que ambos os mecanismos sejam responsáveis pela formação das partículas de carboneto alinhadas que produzem o padrão. Sabendo da diversidade de matérias primas utilizadas que, por sua vez, podiam ser produzidas por diferentes processos, é possível que muitas lâminas forjadas apresentassem padrão formado tanto pelo mecanismo proposto por Sherby apud Charre [4], quanto por aquele proposto por Verhoeven. Sendo assim, a hipótese proposta por Verhoeven apud Charre [4] para explicar - fim da produção das espadas de Damasco devido ao esgotamento do minério não parece satisfatória, pois o mecanismo de formação das faixas proposto por Sherby apud Charre [4] independe da presença de tais impurezas.

\section{REFERÊNCIAS}

I Scott W. The Talisman - A tale of the Crusaders. Edinburgh: Archibald Constable; 1825.

2 Verhoeven JD. Genuine Damascus Steel: a type of banded microstructure in hypereutectoid steels. Steel Res J. 2002;73:356-65.

3 Fiegel LS. On Damascus steel. New York: Atlantis Art Press; I99I.

4 Charre D. The microstructures of steels and cast irons. New York: Springer; 2004. Pmid:15548983. http://dx.doi. org/10.1007/978-3-662-08729-9

5 Smith CS. A history of metallography: the development of ideas on the structure of metals before 1890. Cambridge: The MIT Press; 1988. 
6 Khorasani MM. Arms and armour from Iran. The bronze age to the end of the Qajar Period Germany. Tubinga: Legat Verlag; 2006.

7 Zakey AR. On Islamic swords, studies in Slamic art and architecture in honour of K.A.C. Cairo: Cresswell; 1965.

8 Feuerbach A. Crucible Damascus Steel: A Fascination for Almost 2000 Years. JOM. 2006;58(5):48-50. http://dx.doi. org/ | 0.1007/s| I837-006-0023-y

9 Alexander D. Swords and sabers during the early islamic period. Gladius. 200 I;21:193-220. http://dx.doi. org/10.3989/gladius.200I.86

10 Slaughter C. Espada de Damasco - um produto da civilizaçao islâmica [dissertação de mestrado]. São Paulo: Escola Politécnica, Universidade de São Paulo; 2014.

II Sherby OD, Wadsworth J. Damascus Steels. Sci Am. 1985;252(2): I I2-20. http://dx.doi.org//0.1038/ scientificamerican0285-II2

12 Verhoeven J, Pendray AH, Berge PM. Studies of Damascus steel blades: Part I-Experiments on reconstructed Blades. Mater. Charact. 1993;30(3):175-86. http://dx.doi.org/10.1016/1044-5803(93)90020-V

13 Sherby OD, Wadsworth J. A History of ultrahigh carbon steels. In: Lawrence Livermore National Laboratory. Materials Week '97; I4-I8 Sep 1997; Indianapolis, United States. Livermore: Lawrence Livermore National Laboratory; 1997. p. 42.

14 Oriental arms. [acesso em 3 mar. 20I4]. Disponível em: http://www.oriental-arms.com.

15 Verhoeven J, Pendray A, Gibson ED. Wootz Damascus steel blades. Mater Charact. 1996;37:9-22. http://dx.doi. org/I0.1016/SI044-5803(96)00019-8

16 Molina RC. Contribución al estúdio de la fabricación de armas blancas com acero de Damasc [tese de doutorado]. Madrid: Universidad Complutense de Madrid; 200I.

17 Sherby OD, Wadsworth J. On the Bulat - Damascus steels revisited. Prog Mater Sci. 1980:25(I):35-68. http://dx.doi. org/10.1016/0079-6425(80)900I4-6

18 Callister Jr. Ciência e engenharia de materiais. 8. ed. Rio de Janeiro: LTC; 2012.

19 Needham J. Science and civilization in China, vol. 5, Chemestry and Chemical Technology, Part II. Cambridge: Cambridge University Press; 2004.

20 Feuerbach AM. Crucible steel in Asia: production, use and origins. London: Institute of Archeology, University College London; 2002. PMCid:PMCI50585.

21 Goldenstein H, Yoshimura Hn, Bianchi FF. Infiltration diffusional solidification: a new route for processing metal matrix composites. Mater Sci Technol. 1998; I4(9-10):887-91. http://dx.doi.org/10.1 I79/mst. 1998.14.9-10.887

22 Langford G, Cunningham RE. Steel casting by diffusion solidification. Metall Trans B, Process Metall. 1978;9(I):5-19. http://dx.doi.org/10.1007/BF02822665

23 Charre MD. Les aciers damassés: du fer primitif auxaciers modernes. Paris: Presses de lécole des Mines; 2007.

24 Sherby OD. Ultrahigh carbon steels, Damascus steels and ancient blacksmiths. ISIJ Int. 1999;39:637-48. http:// dx.doi.org/I0.2355/isijinternational.39.637

25 Verhoeven J, Pendray AH, Berge PM. Studies of Damascus steel blades: Part II-Destruction and reformation of the patterns. Mater Charact. 1993;30(3): 187-200. http://dx.doi.org/I0.1016/I044-5803(93)9002I-M

26 Verhoeven J. The mistery of Damascus blades. Sci Am. 200 I;Jan:74-79. Pmid:I I 32427. http://dx.doi.org/I0.1038/ scientificamerican0I0I-74

27 Krauss G. Solidification, segregation, and banding in carbon and alloy steels. Metall Mater Trans B Proc Metall Mater Proc Sci. 2003;34(6):78I-92. http://dx.doi.org/I0.1007/s I 1663-003-0084-z

28 Smith CS. Outstanding researches in metallurgy history. Philadelphia: ASTM; 1963.

29 Verhoeven J. The key role of impurities in ancient Damascus steel blades. JOM. 1998;50(9):58-64. http://dx.doi. org/10.1007/sI I837-998-0419-y

30 Sanchez LG. Claves metalúrgicas de la fabricación de espadas con acero de Damasco según el Taller Persa del Shamshirsaz Assad Allah [tese de doutorado]. Madrid: Universidad Complutense de Madrid; 201 I.

Recebido em: $16 / 01 / 2014$

Aceito em: 07/04/2014 